\title{
Multi-objective Optimization of Water Distribution Systems Based on a Real Options Approach
}

\author{
João Marques ${ }^{1}$, Maria Cunha ${ }^{2}$ and Dragan A. Savić ${ }^{3}$ \\ ${ }^{1}$ Departamento de Engenharia Civil, Faculdade de Ciências e Tecnologia da Universidade de \\ Coimbra, Portugal. \\ 2 Departamento de Engenharia Civil, Faculdade de Ciências e Tecnologia da Universidade de \\ Coimbra, Portugal. \\ ${ }^{3}$ Centre for Water Systems, School of Engineering, Computing and Mathematics, University \\ of Exeter, United Kingdom. \\ 1jmarques@dec.uc.pt, ${ }^{2} m c c u n h a @ d e c . u c . p t,{ }^{3}$ D.Savic@ex.ac.uk
}

This paper describes a multi-objective optimization model including Real Options concepts for the design and operation of water distribution networks. This approach is explained through a case study with some possible expansion areas defined to fit different future scenarios. A multi-objective decision model with conflicting objectives is detailed. Also, environmental impacts are considered taking into account not only the life cycle carbon emissions of the different materials used during the construction of the networks, but also the emissions related to energy consumption during operation. These impacts are translated by giving a cost to each tonne of carbon dioxide emitted. This work presents a new multiobjective simulated annealing algorithm linked to a hydraulic simulator to verify the hydraulic constraints, and the results are represented as points on the Pareto front. The results achieved show that the approach can deal explicitly with conflicting objectives, with environmental impacts and with future uncertainty.

Keywords: carbon emissions, multi-objective optimization, real options, simulated annealing, uncertainty, water networks. 


\section{$1 \quad 1$ Introduction}

2 Water distribution networks today are complex systems that require high investment for

3 their construction and maintenance. The storage and transport of water has been

4 extensively investigated in recent decades by applying optimization techniques to water

5 distribution systems design (Sacks et al. 1989). In developed countries almost everyone

6 has access to water systems, but several problems remain to be solved such as

7 intermittent supply and the high level of water losses. Furthermore, as urban centers

8 continue to grow so does the amount of water used. The networks have to continually

9 adapt to new circumstances to provide an adequate service.

The design of water distribution networks is often viewed as a single-objective,

11 least-cost optimization problem with pipe diameters being the primary decision

12 variables. But when we need to address several objectives, multi-objective optimization

13 can be used to design of water distribution network instead. A number of researchers

14 and practitioners have noted that the optimal design of water distribution systems is a

15 multi-objective issue since it involves compromises between conflicting objectives,

16 such as total cost, reliability and level of service. Savic (2002) demonstrates some

17 shortcomings of single-objective optimization approaches and uses a multi-objective

18 based genetic algorithm (Fonseca and Fleming 1993) to avoid these difficulties.

19 Farmani, et al. (2004), Prasad et al. (2003), Creaco and Franchini (2012) and Todini

20 (2000) explored the application of multi-objective optimization where the minimization

21 of cost and maximization of reliability are the main objectives. Di Pierro et al. (2009)

22 compared two multi-objective algorithms for the design of real size networks. This 
paper describes the solution of a multi-objective optimization model with two conflicting objectives.

This work aims to include the cost of carbon emissions in the design and operation of water networks. We must therefore quantify the emissions from the very beginning of extraction of the different materials used in the water systems until their final disposal. Dennison et al. (1999) use life cycle analysis to compare the environmental impact of different pipe materials. Dandy et al. (2006) developed a multi-objective model that uses sustainability objectives in life cycle cost analysis, energy consumption, greenhouse gas emissions and resources consumption. The tool compared the minimum cost design with the sustainable environmental design. Herstein et al. (2011) presents an index-based method to assess the environmental impact of water supply systems. The index aggregates the consumption of resources, environmental discharges and environmental impacts in a single index. Different materials for tanks, manholes and moorings construction must be used to build up the water supply infrastructure. The most common are: the steel used in pipes, accessories and pumps; reinforced concrete; plastic for pipes and accessories; aggregates for pipeline backfill and asphalt for repaving. The methodology presented Marques et al. (2014a) is used to evaluate the carbon emissions involved, considering the whole life cycle including the extraction of the raw materials, transport, manufacture, assembly, installation, disassembly, demolition and/or decomposition. The methodology also computes carbon emissions from the energy used during the network's operation.

Adding together the partial contributions of pipe installation and energy consumption it is possible to compute the total carbon emissions. It is also necessary to fix a value for the carbon emissions cost for each tonne emitted. These costs are included in the optimization model presented in the next section. 
According to Haimes (1998) the great challenge for the scientific community in the third millennium will be to develop tools and technologies to support and maintain infrastructure. Several methods for the effective planning of water systems have appeared in the literature. If flexible planning can be adopted, the infrastructure will be able to cope with future uncertainty. Real options (ROs), originally from financial theory, could make an important contribution in this area. Myers (1977) was the first to introduce the term real options. Since then a large number of studies have been published where the concepts of ROs have been used in several fields.

A number of studies have developed ROs approaches to solve a variety of problems: Nembhard and Aktan (2010), who systemized applications of ROs to design and resolve engineering problems; De Neufville et al. (2006) report the use of ROs in car parking problems, and Gersonius et al. (2010) apply ROs analysis to the option planning process in urban drainage systems to incorporate flexibility to accommodate climate change while reducing future flood risk. In the water industry, an ROs technique appears in the work of Woodward et al. (2011) to define maritime coastal defenses to reduce the risk of flooding. In the area of water systems expansion, Suttinon and Nasu (2010) present an ROs based approach where the demand increases. Zhang and Babovic (2012) use a ROs approach to evaluate different water technologies in water supply systems under uncertainty. The work of Creaco et al. (2014) proposes a multi-objective methodology aiming at considering the phasing of construction within the design of the water distribution systems, which grow in terms of layout size. The work of Huang et al. (2010) describes the application of ROs to the design of water distribution networks and Basupi and Kapelan (2013) presents a methodology to the flexible and optimal decision making dealing with future demand uncertainty. Finally the authors have already used ROs in two prior works: Marques et al. (2014b) to the optimal design of 
water distribution systems using a single objective model formulation demonstrated in a simple case study and Marques et al. (2014a) taking into account carbon emissions and by using a different single objective model formulation demonstrated in "Anytown network". Here a new multi-objective optimization tool based on simulated annealing is proposed to solve the multi-objective optimization model based on ROs that incorporates two conflicting objectives explicitly. There is a vast body of literature about multi-objective approaches that have been used in several fields: Hakanen et al. (2013) in wastewater treatment plant design and operation; Ahmadi et al. (2014) to calibrate of watershed models for pollutant source identification and watershed management; Giuliani et al. (2014) to the operation of complex environmental systems and Zheng and Zecchin (2014) for designing water distribution systems with multiple supply sources are just some recent examples.

It is very important in water systems planning to predict future operating conditions. However, cities are continually changing and the water supply networks have to be adapted to these changes. Sometimes a new urban or industrial area is built and the network has to be improved to accommodate the new conditions. The opposite can occur in areas where population declines and demand falls. This work presents a multi-objective approach where uncertainty is related to new expansion scenarios for the network.

Some benefits of flexible design are associated with the ease of accommodating different future scenarios. However, flexibility usually incurs an extra cost at the initial stage of a water network design. A flexible design is one that enables the designer, developer, or operator to actively manage or further develop the configuration of the system downstream, to adapt it to changes in the supply, demand, or economic environment. The ROs approach presented in this work uses a decision tree to reflect 
different scenarios that may occur during the planning horizon. The process uses a multi-objective optimization model to find solutions for the first period and for different possible future realities according to the decision tree. The model uses two objectives: a minimum cost objective function that takes into account the carbon emission costs and a level of service measure that minimizes the pressure failures that can occur over the entire planning horizon. Various scenarios are analyzed to predict different alternative future conditions.

The new ROs approach presented in this work deals with future uncertainties and with two conflicting objectives, over the whole planning horizon. Decision planning based on trying to delay some decisions for the future, enables current investment to be reduced. This delay also incurs some costs because the initial solution has to be flexible enough to accommodate all the future conditions, and such flexibility comes at a price.

The remainder of this paper is organized as follows: in the next section the ROs framework and the case study are set out. This is followed by a multi-objective decision model based on an ROs approach, and then the results are presented. Finally, the conclusions are set out.

\section{Real options framework and case study}

A real options approach makes it possible to consider different adaptations over the lifetime horizon, according to urban growth. Areas can become depopulated or urbanized. These modifications have impacts on the hydraulic behavior of the networks and should be taken into account. In this section a case study demonstrating how the multi-objective model considering ROs can be employed is presented. Figure 1 represents a water distribution network inspired on the work of Walski et al. (1990). In the original case study the layout of the network is only the part represented inside the 
122 dashed line. However, in this case study the possibility to expand the network for four

123 different areas A1, A2, A3 and A4 it is considered. Furthermore an area A5 where it is 124 possible to have a depopulated area is taken into account.

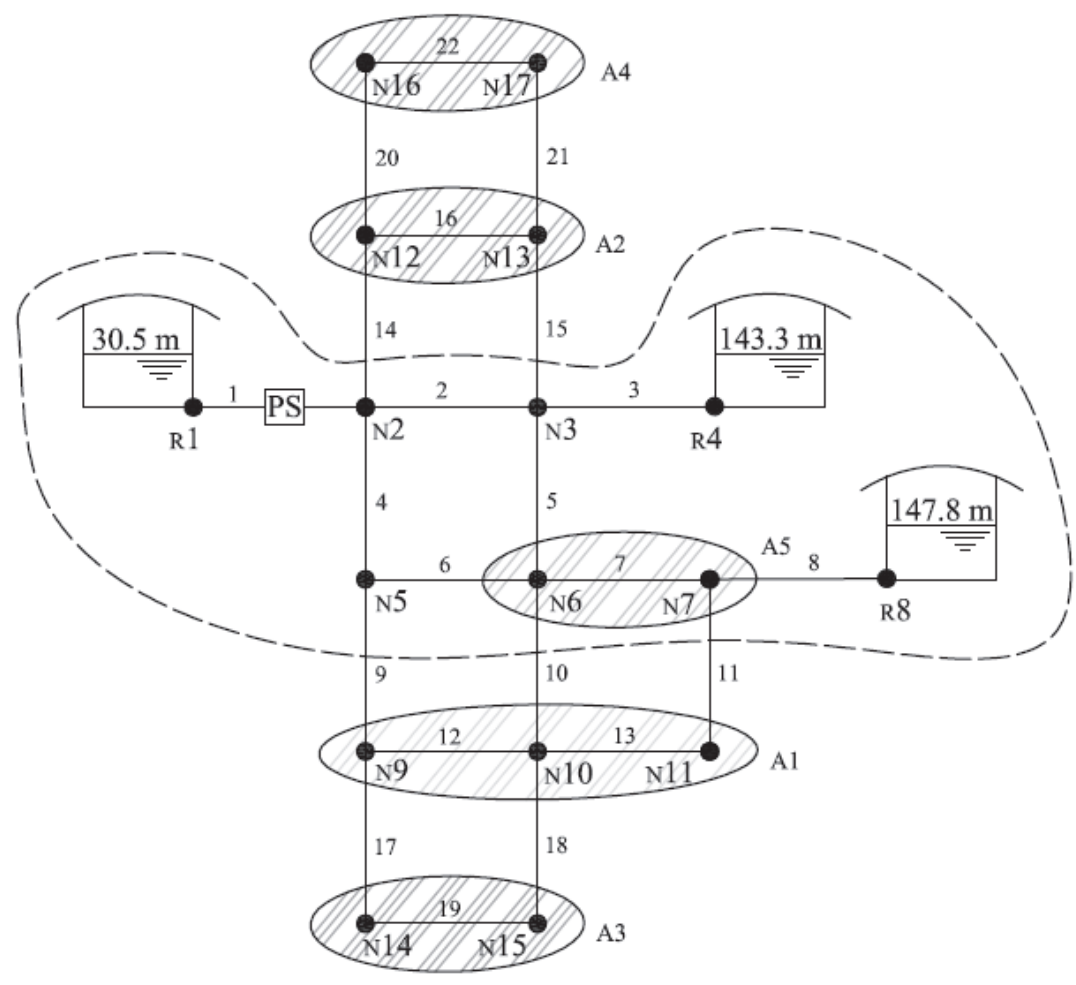

The network is supplied by three fixed-level reservoirs and there is a pumping

128 station placed at link 1 to transmit energy to the flow from reservoir R1. The

129 characteristics of the nodes at demand conditions (1) and (2) are presented in Table 1.

130 This work considers two kinds of minimum pressure: the desired pressure and the

131 admissible pressure of reference. The lower limit of pressures (admissible pressures) is

132 assumed to be high enough to permit that the demand can be totally satisfied. Pressure

133 deficits for which the demand cannot be totally satisfied (Wagner et al. 1988) are not

134 considered here. The two different pressure levels are included to analyse the tradeoff

135 between costs and service levels measured in terms of minimum nodal pressures that are

136 desired and pressures that are effectively provided. 
138 simplification of the problem and the daily consumption is 20 hours at demand

139 condition (1) with the other 4 hours at demand condition (2). The energy costs are

$140 \quad 0.075 \$ / \mathrm{KWh}$ and should be evaluated for a 60 -year period using a discount rate of $4 \%$

141 year. The discount rate is just used to assess the cost in different time interval of the

142 planning horizon. This rate was fixed based on the work of Wu et al. (2010).

143 Table 1: Characteristics of the nodes

\begin{tabular}{|c|c|c|c|c|c|c|c|c|}
\hline \multirow[t]{2}{*}{ Node } & \multirow[t]{2}{*}{ Areas } & \multirow{2}{*}{$\begin{array}{l}\text { Ground } \\
\text { elevation } \\
\text { (m) }\end{array}$} & \multicolumn{2}{|c|}{ Nodal consumption (1/s) } & \multicolumn{2}{|c|}{$\begin{array}{l}\text { Minimum desirable } \\
\text { pressure }(\mathrm{m})\end{array}$} & \multicolumn{2}{|c|}{$\begin{array}{l}\text { Minimum admissible } \\
\text { pressure }(\mathrm{m})\end{array}$} \\
\hline & & & (1) & (2) & (1) & (2) & (1) & (2) \\
\hline 1 & & 36.48 & \multicolumn{6}{|c|}{ Reservoir at the level of $35.48 \mathrm{~m}$} \\
\hline 2 & & 30.48 & 0 & 0 & 28.132 & 17.583 & 21.099 & 10.550 \\
\hline 3 & & 106.68 & 31.545 & 47.318 & 28.132 & 17.583 & 21.099 & 10.550 \\
\hline 4 & & 117.35 & \multicolumn{6}{|c|}{ Reservoir at the level of $151.73 \mathrm{~m}$} \\
\hline 5 & & 106.68 & 31.545 & 47.318 & 28.132 & 17.583 & 21.099 & 10.550 \\
\hline 6 & A5 & 106.68 & 126.180 & 189.270 & 28.132 & 17.583 & 21.099 & 10.550 \\
\hline 7 & A5 & 106.68 & 63.090 & 94.635 & 28.132 & 17.583 & 21.099 & 10.550 \\
\hline 8 & & 121.92 & \multicolumn{6}{|c|}{ Reservoir at the level of $156.30 \mathrm{~m}$} \\
\hline 9 & $\mathrm{~A} 1$ & 106.68 & 31.545 & 47.318 & 28.132 & 17.583 & 21.099 & 10.550 \\
\hline 10 & A1 & 106.68 & 31.545 & 47.318 & 28.132 & 17.583 & 21.099 & 10.550 \\
\hline 11 & A1 & 106.68 & 31.545 & 47.318 & 28.132 & 17.583 & 21.099 & 10.550 \\
\hline 12 & A2 & 106.68 & 31.545 & 47.318 & 28.132 & 17.583 & 21.099 & 10.550 \\
\hline 13 & $\mathrm{~A} 2$ & 106.68 & 31.545 & 47.318 & 28.132 & 17.583 & 21.099 & 10.550 \\
\hline 14 & $\mathrm{~A} 3$ & 106.68 & 31.545 & 47.318 & 28.132 & 17.583 & 21.099 & 10.550 \\
\hline 15 & $\mathrm{~A} 3$ & 106.68 & 31.545 & 47.318 & 28.132 & 17.583 & 21.099 & 10.550 \\
\hline 16 & A4 & 106.68 & 31.545 & 47.318 & 28.132 & 17.583 & 21.099 & 10.550 \\
\hline 17 & A4 & 106.68 & 31.545 & 47.318 & 28.132 & 17.583 & 21.099 & 10.550 \\
\hline
\end{tabular}

144

145 This is a new network that considers the 8 different commercial diameters

146 available for the pipe design presented in Table 2. The installation of parallel pipes

147 during the planning horizon is not considered in this study. Carbon emissions are

148 computed assuming a value of $0.637 \mathrm{KgCO} 2$ per each $\mathrm{KWh}$ of energy produced. This is

149 a mean value of the carbon emissions of the electricity generation sector between 2005

150 and 2010 in Portugal (ERSE 2012). The characteristics of the pipes are given in Table 3. 
151 Table 2: Diameter, unit cost, carbon emissions and Hazen-Williams coefficients

\begin{tabular}{|c|c|c|c|}
\hline $\begin{array}{l}\text { Diameters } \\
(\mathrm{mm})\end{array}$ & $\begin{array}{l}\text { Unit cost } \\
(\$ / \mathrm{m})\end{array}$ & $\begin{array}{l}\text { Carbon } \\
\text { emissions } \\
\left(\mathrm{TonCO}_{2} / \mathrm{m}\right)\end{array}$ & $\begin{array}{l}\text { Hazen- } \\
\text { Williams } \\
\text { coefficients }\end{array}$ \\
\hline 152.4 & 49.541 & 0.48 & 100 \\
\hline 203.2 & 63.32 & 0.59 & 100 \\
\hline 254 & 94.816 & 0.71 & 100 \\
\hline 304.8 & 132.874 & 0.81 & 100 \\
\hline 355.6 & 170.932 & 0.87 & 100 \\
\hline 406.4 & 194.882 & 0.96 & 100 \\
\hline 457.2 & 225.066 & 1.05 & 100 \\
\hline 508 & 262.795 & 1.14 & 100 \\
\hline
\end{tabular}

152

153 Table 3: Characteristics of the pipes

\begin{tabular}{l|l|l|l|l}
\hline Pipe & $\begin{array}{l}\text { Initial } \\
\text { node }\end{array}$ & $\begin{array}{l}\text { Final } \\
\text { node }\end{array}$ & Length $(\mathrm{m})$ & Area \\
\hline \hline 1 & 1 & 2 & Pump & \\
2 & 2 & 3 & 3218.688 & \\
3 & 3 & 4 & 3218.688 & \\
4 & 2 & 5 & 1609.344 & \\
5 & 3 & 6 & 1609.344 & \\
6 & 5 & 6 & 3218.688 & \\
7 & 6 & 7 & 3218.688 & \\
8 & 7 & 8 & 1609.344 & \\
9 & 5 & 9 & 1609.344 & A1 \\
10 & 6 & 10 & 1609.344 & A1 \\
11 & 7 & 11 & 1609.344 & A1 \\
12 & 9 & 10 & 3218.688 & A1 \\
13 & 10 & 11 & 3218.688 & A1 \\
14 & 2 & 12 & 1609.344 & A2 \\
15 & 3 & 13 & 1609.344 & A2 \\
16 & 12 & 13 & 3218.688 & A2 \\
17 & 9 & 14 & 1609.344 & A3 \\
18 & 10 & 15 & 1609.344 & A3 \\
19 & 14 & 15 & 3218.688 & A3 \\
20 & 12 & 16 & 1609.344 & A4 \\
21 & 13 & 17 & 1609.344 & A4 \\
22 & 16 & 17 & 3218.688 & A4 \\
\hline
\end{tabular}


156 subdivided into 3 stages of 20 years. The decision tree contemplates 8 possible

157 scenarios where different conditions can occur in future time intervals. The different

158 decision paths that can be taken are schematized through the tree shown in Fig. 2.

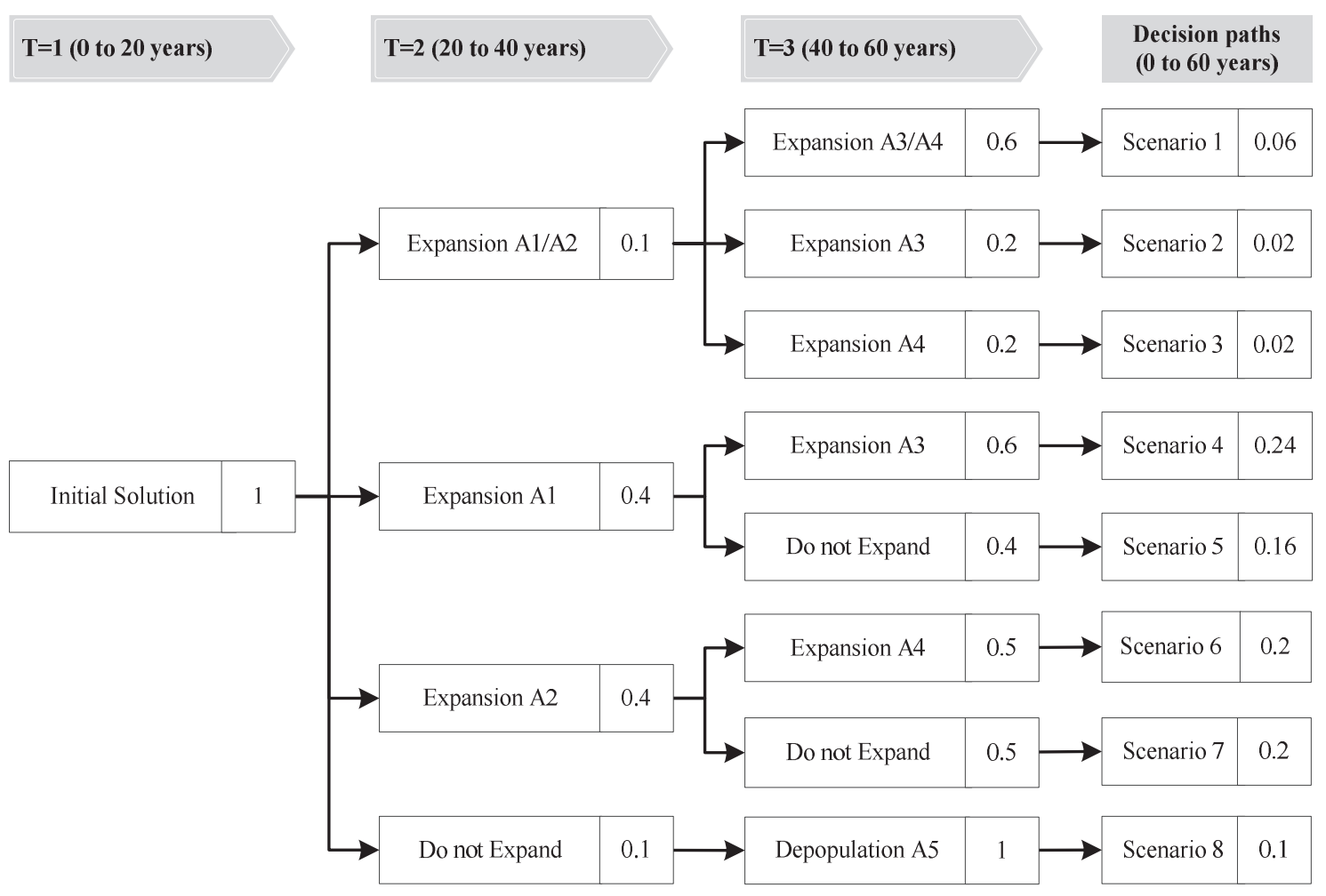

Figure 2: Decision tree for the planning horizon and probabilities of occurrence

Each decision path has different probabilities. For this case study the probabilities considered for the different decision nodes are shown in the square boxes of Fig. 2. For real case studies, these probabilities have to be defined by decision makers using appropriate methods and knowledge. The values shown in the last branches of the decision tree are the probabilities of the scenarios and are calculated by multiplying the probabilities of all nodes on the path of that scenario. For the first period $\mathrm{T}=1$ an initial design for the network is defined. For $\mathrm{T}=2$, four different situations can occur, expansion to $\mathrm{A} 1$ and $\mathrm{A} 2$, expansion to $\mathrm{A} 1$, expansion to $\mathrm{A} 2$ and no expansion. In the last period $\mathrm{T}=3$, new expansion areas are possible, A3 and A4, 
expansion to A3, expansion to A4 and no expansion. It is also possible to have a

172 depopulated area A5 where the consumption could decrease by $30 \%$. These scenarios,

173 included in the decision tree of Fig. 2, are deemed the most probable future conditions

174 for the case study. ROs permits an adaptive planning strategy and if the predicted future

175 conditions turn out to be wrong, the model could be rerun for more realistic scenarios.

176 This paper deals with a small water network example. In real-world large

177 networks with many pipes and with many possible plans for upgrades, the decision tree

178 can become very complex. However, the methodology presented here does allow

179 numerous scenarios to be defined, and there is no restriction on the number of

180 possibilities. However, the aim is to keep the number of options relatively small by

181 taking into account the most probable future scenarios for the water network. In that

182 case, the decision trees are easy to understand and can be easily handled by decision

183 makers and the methodology.

Finally a cost must be assigned to the carbon emissions. A carbon cost of $5 \$$ for each ton of carbon emitted is assumed here. This cost is defined according to European

186 Energy Exchange 2013-2020 data.

\section{Optimization model}

188 This work presents a multi-objective model with two conflicting objectives. One of the objectives consists in minimizing the costs of construction and operations of the network. These systems are responsible for important carbon emissions during

191 construction but mostly during the operation phase. Therefore, the carbon emissions are

192 also computed to try to achieve an environmental friendly design for the water

193 distribution system. The other objective of the model is used to determine a solution 
194 taking into account the level of service. As it was stated, the model considers two kinds

195 of minimum pressures, the minimum desirable pressures and the minimum admissible

196 pressures. If nodal pressure remains between these two limits, the pressure violations

197 are summed for all nodes. However the model considers that the network has to obey

198 the desirable pressure constraints for the first 20 years. In the subsequent time intervals,

199 pressures can decrease up to admissible pressures, according to the probability of

200 occurrence of the decision paths.

Eq. 1.

$$
O F 1=\operatorname{Min}(C i+C f)
$$

212 the first period $\mathrm{T}=1$ of planning and is given by Eq. 2.

213

$$
C i=\left(\sum_{i=1}^{N P I}\left(\text { Cpipe }_{i, 1}+C C \text { Epipe }_{i, 1}\right)+\sum_{j=1}^{N P U}\left(C p s_{j, 1}\right)+\sum_{d=1}^{N D C}\left(C e_{d, 1}+C C E e_{d, 1}\right)\right)
$$

Where: 
Cpipe $_{i, 1}$ - cost of pipe $i$ in period $T=1$;

CCEpipe $_{i, 1}$ - cost of the carbon emissions of pipe $i$ in period $T=1$; $N P U$ - number of pumps in the network;

$C p s_{j, 1}$ - pumping station costs of pump $j$ in the period $T=1$; condition $d$ in period $T=1$.

The initial cost is given by the sum of the cost of pipes, the cost of pumps and the present value of energy cost. The carbon emissions' cost of pipes and energy are also included. The carbon emissions related to other network elements as pumps are not considered, since they are neglected compared with pipe construction and energy. The other term of the objective function $O F 1$ represents the future cost of all the scenarios (Eq. 3), weighted by the corresponding probability of each scenario.

231

$$
C f=\sum_{\mathrm{s}=1}^{N S} \sum_{\mathrm{t}=2}^{N T I}\left(\text { Cfuture }_{t, s} \cdot \prod_{n t=2}^{t} \text { prob }_{n t, s}\right)
$$

Where:

The future scenarios' costs are arrived at by summing all possible future costs, starting from $\mathrm{T}=2$. These costs are computed by multiplying the cost of each decision 
possible costs for the network. The term Cfuturet,s is computed in Eq. 4, for all periods

241 beginning in $T=2$ (the costs for the first period are already calculated in the Cinitial

242 term).

$$
\begin{aligned}
\text { Cfuture }_{t, s} & =\left(\sum_{i=1}^{N P I}\left(\text { Cpipe }_{i, t, s}\right)+\sum_{j=1}^{N P U}\left(\operatorname{Cps}_{j, t, s}\right)+\sum_{d=1}^{N D C}\left(C e_{d, t, s}\right)\right) \cdot \frac{1}{(1+I R)^{Y_{t}}}+ \\
& +\left(\sum_{i=1}^{N P I}\left(\text { CCEpipe }_{i, t, s}\right)+\sum_{d=1}^{N D C}\left(\text { CCEe }_{d, t, s}\right)\right)
\end{aligned}
$$

Where:

$N P I$ - number of pipes in the network;

Cpipe $_{i, t}$ - cost of pipe $i$ installed in period $t$ in scenario $s$;

$N P U$ - number of pumps in the network;

The first term of Eq. 4 computes the cost of pipes to be installed for different decision paths plus the costs to install pumps every 20 years plus the cost of energy. The current value of these cost are then determined. To compute the current value of the costs of energy, it is necessary to sum and discount the costs during the number of years 
year zero of the planning horizon. The carbon emission costs associated with pipe installation and with energy consumption are included in the second term.

The sum of the initial costs with future costs is intended to represent the full planning horizon of the network, considering future uncertainty. The model aims to determine the decision variables not only for the first period but also for all the future decisions that have to be taken according to certain possible decision paths. The values of the decision variables that are achieved for the first period are effectively the ones that are needed to be adopted now. minimize the total pressure violations for the different future scenarios.

$$
O F 2=\operatorname{Min}(T P V)
$$

Where:

pressure violations. The total pressure violations are computed according to Eq. 6:

$$
T P V=\sum_{\mathrm{s}=1}^{N S} \sum_{\mathrm{t}=2}^{N T I} \sum_{\mathrm{d}=1}^{N D C} \sum_{n=1}^{N N} \operatorname{Max}\left\{0 ;\left(P d e s_{\min , n, d}-P_{n, d, t, s}\right)\right\}
$$

Where: scenario $s$.

Eq. 6 computes the sum of pressure violations for each scenario, each time interval (starting from $\mathrm{T}=2$ ), each demand condition and each network node. This sum 
of pressure violations can be used as a measure of the network performance during the entire planning horizon.

Table 1 presents the desirable and admissible minimum pressures for each node.

287 However these admissible pressures are a threshold limit to compute the lowest value that the nodal pressures can reach according to the probability of scenarios. The constraint presented in expression (7) aims to obtain higher values, and thus less pressure violations, for scenarios with high probabilities of occurrence. In the first time interval, a decision node with probability equal to 1 is only considered. If in expression (7) the probability is set to 1 , the minimum pressure become equal to the desired pressure. Thus, for the first time interval the pressures have to be higher or equal to

294 desirable pressures and no violations are permitted in the first time stage.

$$
\begin{aligned}
P_{n, d, t, s} & \geq\left\{\prod_{n t=2}^{t} \operatorname{prob}_{n t, s}\left(\operatorname{Pdes}_{\min , n, d}-P a d m_{\min , n, d}\right)+P a d m_{\min , n, d}\right\} \\
\forall n & \in N N ; \forall d \in N D C ; \forall n t \in N T I ; \forall s \in N S
\end{aligned}
$$

Where: condition $d$. Expression (7) is just one of the constraints of the model. The model also includes other constraints: Eq. (8) to verify the nodal continuity equations; Eq. (9) to 300 compute the head loss of the pipes; Eq. (10) to guarantee a minimum diameter for the

301 pipes; Eq. (11) so the candidate discrete diameter for each pipe is based on a set of commercial diameters; and Eq. (12) to ensure the assignment of only one commercial diameter for each pipe. The decision variables of this optimization problem described by Eq. (1 to 12) are the commercial pipe diameter assigned to each pipe of the network. 


$$
\sum_{i=1}^{N P I} I_{n, i} Q_{i, d, t, s}=Q C_{n, s} \quad \forall n \in N N ; \forall d \in N D C ; \forall t \in N T I ; \forall s \in N S
$$

$$
\Delta H_{i, d, t, s}=K_{i} Q_{i, d, t, s}{ }^{\alpha} \quad \forall n \in N N ; \forall d \in N D C ; \forall t \in N T I ; \forall s \in N S
$$

$$
D_{i} \geq D \min _{i} \quad \forall i \in N P I
$$

$$
D_{i}=\sum_{d=1}^{N D} Y D_{d, i} . \operatorname{Dcom}_{d, i} \quad \forall i \in N P I
$$

$$
\sum_{d=1}^{N D} Y D_{d, i}=1 \quad \forall i \in N P I
$$

Where:

$I_{n, i}$-incidence matrix of the network;

$$
s\left(\mathrm{~m}^{3} / \mathrm{s}\right)
$$

$Q C_{n, d, t, s}$ - consumption in node $n$ in demand condition $d$ for period $t$ and scenario $s\left(\mathrm{~m}^{3} / \mathrm{s}\right)$; $N N$ - number of nodes; $\Delta H_{i, s}$ - head loss in pipe $i$ in demand condition $d$ for period $t$ and scenario $s$; $K_{i}, \alpha$ - coefficients that depends of the physic characteristics of the pipe $i$; $D_{i}$ - diameter of pipe $i$

$D \operatorname{Din}_{i}$ - minimum diameter for the pipe $i$; $Y D_{d, i}$ - binary variable to represent the use of the diameter $d$ in pipe $i$; $\operatorname{Dcom}_{d, i}$ - commercial diameter $d$ assigned to pipe $I$; $N D$ - number of commercial diameters. 


\section{Optimization tool}

326 A new method has been developed to solve the multi-objective model. This work

327 presents a multi-objective simulated annealing algorithm inspired by the work of

328 Bandyopadhyay et al. (2008). In these problems the objective is to search for a group of optimal solutions that are normally named "optimal Pareto front", introduced by Pareto

330 (1896). These solutions are characterized by the fact that it is not possible to enhance one objective without worsening the other.

The original simulated annealing method for single-objective problems proposed by Kirkpatrick et al. (1983) needs some changes before multi-objective optimization problems can be solved. A fundamental difference is the use of a dominance concept to guide the exploration of neighborhoods during the search process. The concept of dominance is generally used to compare two solutions $S_{i}$ and $s_{j}$. If $s_{i}$ is not worse for all the objectives than $s_{j}$ and only better for at least one objective, it is said that $S_{i}$ dominates $s_{j}$. Also, a solution $s_{\text {opt }}$ is said to be non-dominated if no other feasible

340 Pareto optimal front. far are stored. The structure of the proposed optimization tool is presented in Fig 3. 
360

361

362 Figure 3: Multi-objective simulated annealing flow chart 
annealing tool: the initial solution, the annealing parameters, the building method of the neighborhoods, the cooling process and the stop criteria that are given in the work of

367 Cunha \& Sousa (2001) are also used in this method. But some important differences are 368 highlighted below.

After the generation of a candidate solution and verification of the constraints of the model we must check the domination status. This is the key difference between the single-objective and multi-objective tools based on simulated annealing. In the singleobjective method the candidate solution is accepted according to the Metropolis criterion that compares the current solution with the candidate solution. However, in this multi-objective method the candidate solution is compared both with the current solution and with the solutions saved in the archive.

The dominance between two solutions is computed by Eq. 13:

$$
\Delta d o m_{a, b}=\prod_{i=1, O F_{i}(a) \neq O F_{i}(b)}^{N}\left|O F_{i}(a)-O F_{i}(b)\right|
$$

$\Delta d o m_{a, b}-$ dominance $a$ to $b$; $N$ - total number of objectives; $O F_{i}(a)$-value of objective function $i$ for solution $a$; $O F_{i}(b)$ - value of objective function $i$ for solution $b$.

The dominance between two solutions is computed by multiplying the change in the values of the $N$ objectives, if this difference is other than zero. The domination concept is explained in Fig. 4 for the example of two objective functions. 


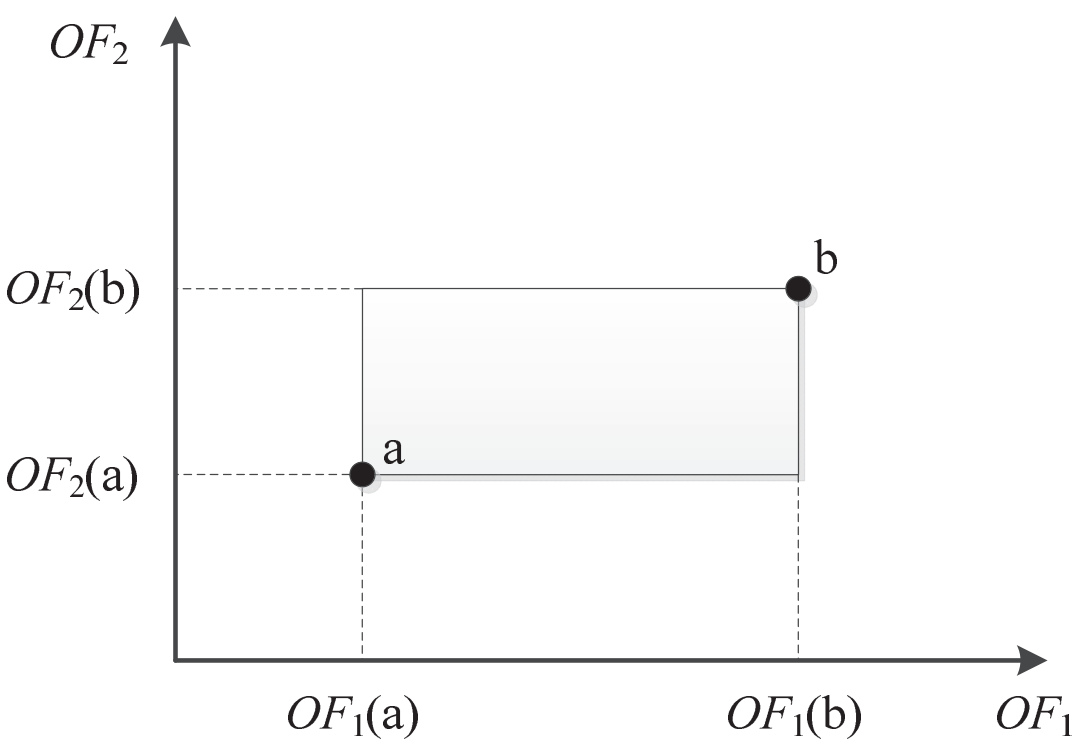

387 Figure 4: Domination between solutions $a$ and $b$, adapted from Bandyopadhyay et al. $388 \quad(2008)$ The amount of domination is represented in Fig. 4 by the area of the rectangle between solutions $a$ and $b$ and is used by the multi-objective simulated annealing to compute the acceptance probability. Three different conditions can occur when checking the domination status: current solution dominates candidate solution; candidate and current solutions are nondominated and candidate solution dominates current solution. According to the domination status, it can also be necessary to compute the dominance of the candidate solution in relation to the solution in the archive. According to the situation, the solution

397 can be accepted directly and become the new current solution. But, if the candidate

398 solution is dominated by current solution or by the archive, a metropolis criterion is used to compute the acceptance probability for three distinct cases of dominance, as presented in Fig. 3. For case 1, the dominance is computed by Eq. 14:

$$
\Delta d o m_{\text {mean }}=\frac{\left(\sum_{i=1}^{p} \Delta d o m_{i, \text { cand }}\right)+\Delta d o m_{\text {curr }, \text { cand }}}{p+1}
$$


Where:

403

404

405

406

407

408

409

410

411

412

413

414

415

416

417

418

419

420

421

422

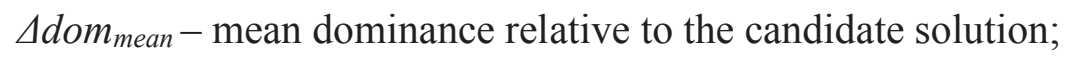

$\Delta d o m_{i, c a n d}-$ dominance of the archive relative to the candidate solution; $\Delta d o m_{\text {curr,cand }}$ - dominance of the current solution relative to the candidate solution;

$p$ - total number of solutions in the archive that dominate the candidate solution.

Eq. 9 considers not only the dominance of the current solution in relation to the candidate solution, but also the sum of dominance of all the solutions in the archive that dominate the candidate solution. This sum is divided by the number of solutions in the archive that dominate the candidate solution, plus one, to take into account the dominance of the current solution relative to the candidate solution. For case 2, the current and candidate solutions are non-dominated and the mean dominance is computed by Eq. 15:

$\Delta d o m_{\text {mean }}=\frac{\left(\sum_{i=1}^{p} \Delta d o m_{i, \text { cand }}\right)}{p}$

This expression is analogous to case 1 , except that now the dominance between the current and candidate solutions is not taken into account. Lastly, for case 3 , the candidate solution dominates the current solution. But if the archive dominates the candidate solution a minimum dominance is computed through Eq. 16, deemed equal to the minimum value of dominance between the solutions of the archive that dominate the candidate solution.

$\Delta d o m_{\min }=\operatorname{Min}\left(\Delta d o m_{i, c a n d}, i=1, \ldots p\right)$ 
Where:

$\Delta d \operatorname{dm}_{\min }-$ minimum dominance relative to candidate solution.

425

426

430

$$
\begin{aligned}
& P_{a c p}=\exp \left(\frac{-\Delta d o m_{\text {mean }}}{T}\right) \\
& P_{a c p}=\exp \left(\frac{-\Delta d o m_{\text {min }}}{T}\right)
\end{aligned}
$$
the candidate solution. For case 3, if the Metropolis criterion is met the current solution

434 becomes equal to the solution of the archive with the minimum dominance relative to the candidate solution. These movements are also called uphill moves because they are contrary to the direction to the minima can be accepted according to the computed probabilities. This method is thus able to explore, in theory, the full solution space and 438 the solutions achieved, regardless of the starting point of the algorithm.

According to the structure of the algorithm of Fig. 3, the multi-objective process

440 is repeated for a number of iterations at each temperature. The temperature is reduced 441 until the stop criteria are attained and the process stops. 
444 process, solutions are stored in the archive until it is completed with $S L$ solutions. Then

445 a clustering technique is used to lower the number of solutions stored to the lower limit

$446 L L$. The clustering technique is based on the work of Hartigan and Wong (1979). This

447 tool aims to find a small number of $L L$ solutions that represents the group of $S L$

448 solutions. The values are $L L=10$ and $S L=30$ and are defined according to the number of

449 final of Pareto front solutions that we wish to obtain.

This optimization method was linked to the EPANET hydraulic simulator

451 (Rossman, 2000) to verify the hydraulic constraints of the multi-objective model.

452 Although this is a demand driven hydraulic simulator, the methodology included in this paper could be easily adapted for a pressure driven hydraulic simulator to include issues related to network deterioration and leakages.

In this work a simple water network it is used to illustrate the approach. For

456 large size networks the computation demand increases due to the size of the network,

457 which has impacts on how quickly the RO problem can be solved. For large networks, if 458 the computation time increases too much, some strategies can be used to overcome this problem: considering just the more important parts or by dividing the network in subzones, such as district metered areas (DMAs) or using parallel computing.

\section{$461 \quad 5$ Results}

462 Figure 5 provides some results obtained by solving the multi-objective model given by

463 the objective functions and constraints (Eq. 1 to 12). The model determines the Pareto

464 front consisting of 10 different solutions. The total cost represents not only the

465 investment and operation costs but also the carbon emission costs of the network

466 lifecycle. The minimum pressure violations are arrived at by summing all the violation 


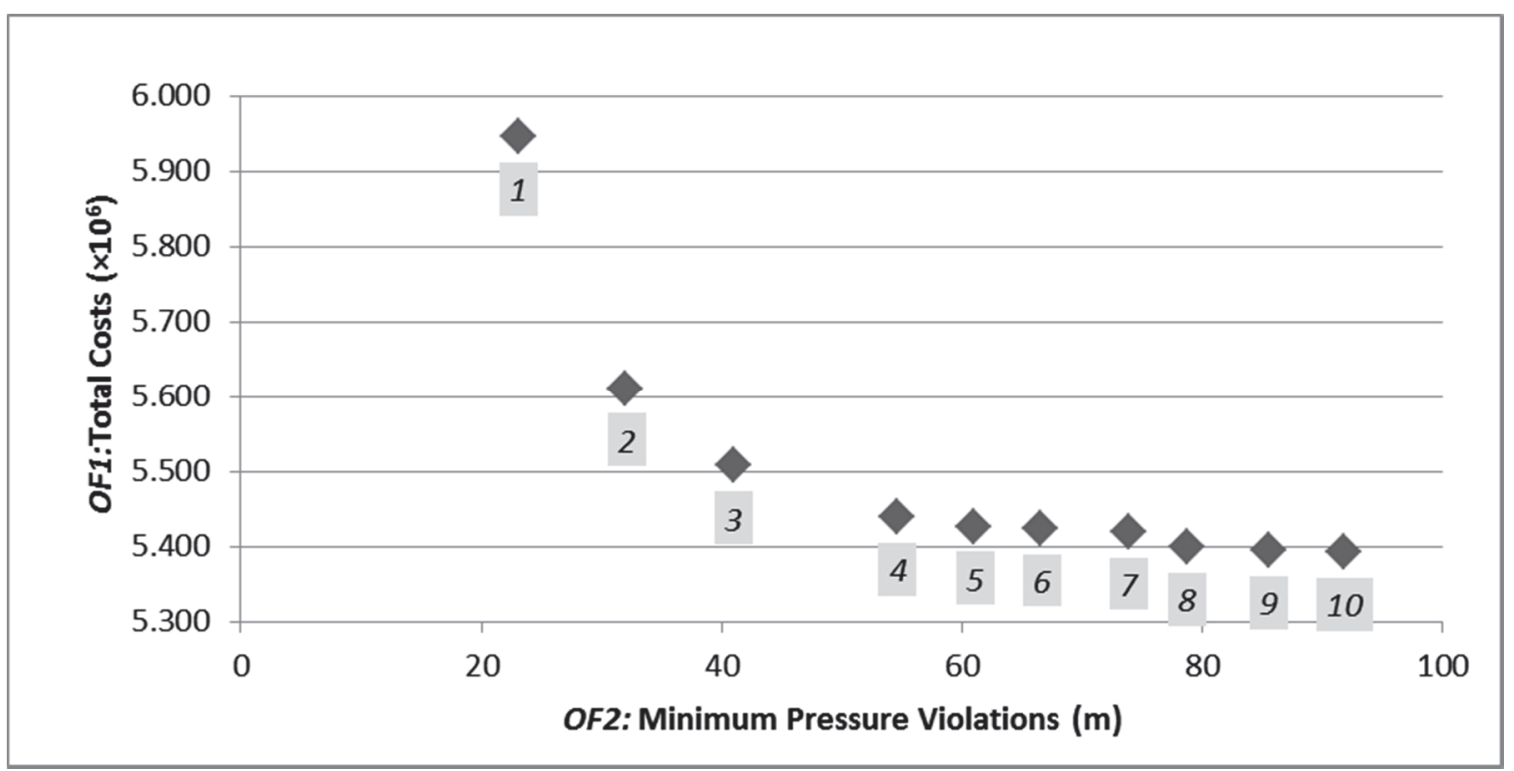

Figure 5: Pareto front of objectives $O F 1$ and $O F 2$

The Pareto front that can be traced through the points represented in Fig. 5 gives an idea about how the cost decreases when pressure violations are permitted. Fig.5 provides the Pareto front identified by the optimization tool. This figure represents 10 distinct solutions. The number of solutions is given a by the lower limit of the archive $L L$. This limit is defined according to the number of final solutions required. If it is necessary to identify a high number of solutions, with the objective to obtain an extended Pareto Front in terms of cost (Higher costs than $5.784 \times 10^{6}$ ) or lower pressure violations (lower than $23 \mathrm{~m}$ ) the number of final solutions has to increase. However, the computational effort will also increase. These 10 solutions were achieved in approximately $2.5 \times 10^{5}$ evaluations. Details of the cost of pipes, pumps and energy (PPE), carbon emission costs, total costs and total pressure violations for each solution of the Pareto front are given in Table. 4. 
Table 4: Pareto front solutions

\begin{tabular}{l|l|l|l|l|l|l|l|l|l|l}
\hline Solution & 1 & 2 & 3 & 4 & 5 & 6 & 7 & 8 & 9 & 10 \\
\hline \hline PPE cost $\$\left(\times 10^{6}\right)$ & 5.784 & 5.461 & 5.358 & 5.291 & 5.279 & 5.276 & 5.273 & 5.253 & 5.248 & 5.246 \\
Carbon cost $\$\left(\times 10^{6}\right)$ & 0.161 & 0.150 & 0.149 & 0.148 & 0.148 & 0.148 & 0.147 & 0.147 & 0.146 & 0.146 \\
Total cost $\$\left(\times 10^{6}\right)$ & 5.945 & 5.611 & 5.507 & 5.439 & 5.427 & 5.424 & 5.420 & 5.399 & 5.395 & 5.392 \\
Pressure Viol. $(\mathrm{m})$ & 23 & 32 & 41 & 55 & 61 & 67 & 74 & 79 & 85 & 92 \\
\hline
\end{tabular}

486

Table 4 also shows that the total cost falls if high pressure violations are

allowed. A higher level of service requires an increase in the network capacity to meet

the minimum desirable pressures of the network. We can also see that for solutions 10

to 4 a small increment in the total cost makes it possible to define solutions with significant falls in the total minimum pressure violations. Thus, it is possible to improve the level of service of the network within this range of solutions for a low expenditure.

The carbon emission varies for different solutions on the Pareto front between a minimum of $\$ 146,227$ for solution 10 and a maximum of $\$ 161,019$ for solution 1 . In fact, the variation in carbon costs for these 10 solutions is small and thus the impact on

497 the optimization process is low. This value is nonetheless included in the model to 498 quantify the carbon emissions involved in construction and operation of water networks.

500 (solution 1 and solution 10) will be detailed next, just for the first scenario.. Fig 6 shows

501 the total cost of the solution 1 , for scenario 1 and for the 60 -year planning horizon, is

$502 \$ 7,455,992$ and is composed of PPE costs of $\$ 7,260,067$ and carbon emission costs of

$503 \$ 195,925$, associated with the design and operation of the network. The total cost of

504 solution 10 (Fig. 7) for the same scenario and for the 60-year planning horizon, is 
$505 \$ 7,068,095$ and consists of PPE costs of $\$ 6,883,401$ and carbon emission costs of

$506 \$ 184,694$. In this scenario all the areas are expanded, thus the total consumption in the

507 network increases. This is the most demanding case considered in the decision tree and

508 has a $6 \%$ probability of occurrence. The diameters are given in millimeters and the

509 expansion areas are indicated by traced ellipses aggregating the new consumption

510 nodes.

511

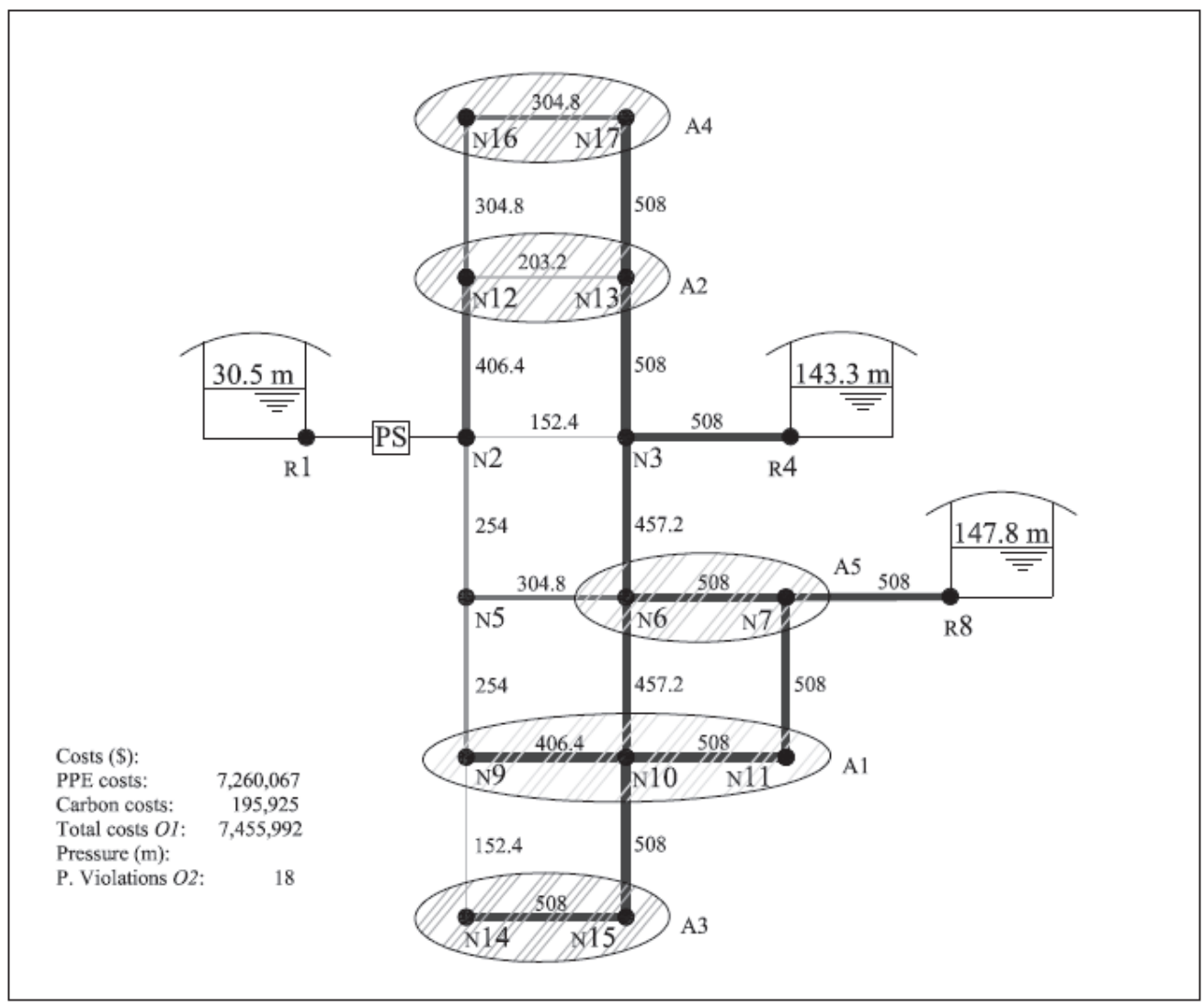

512 Figure 6: Design for solution 1 and considering scenario 1 in the last time interval 


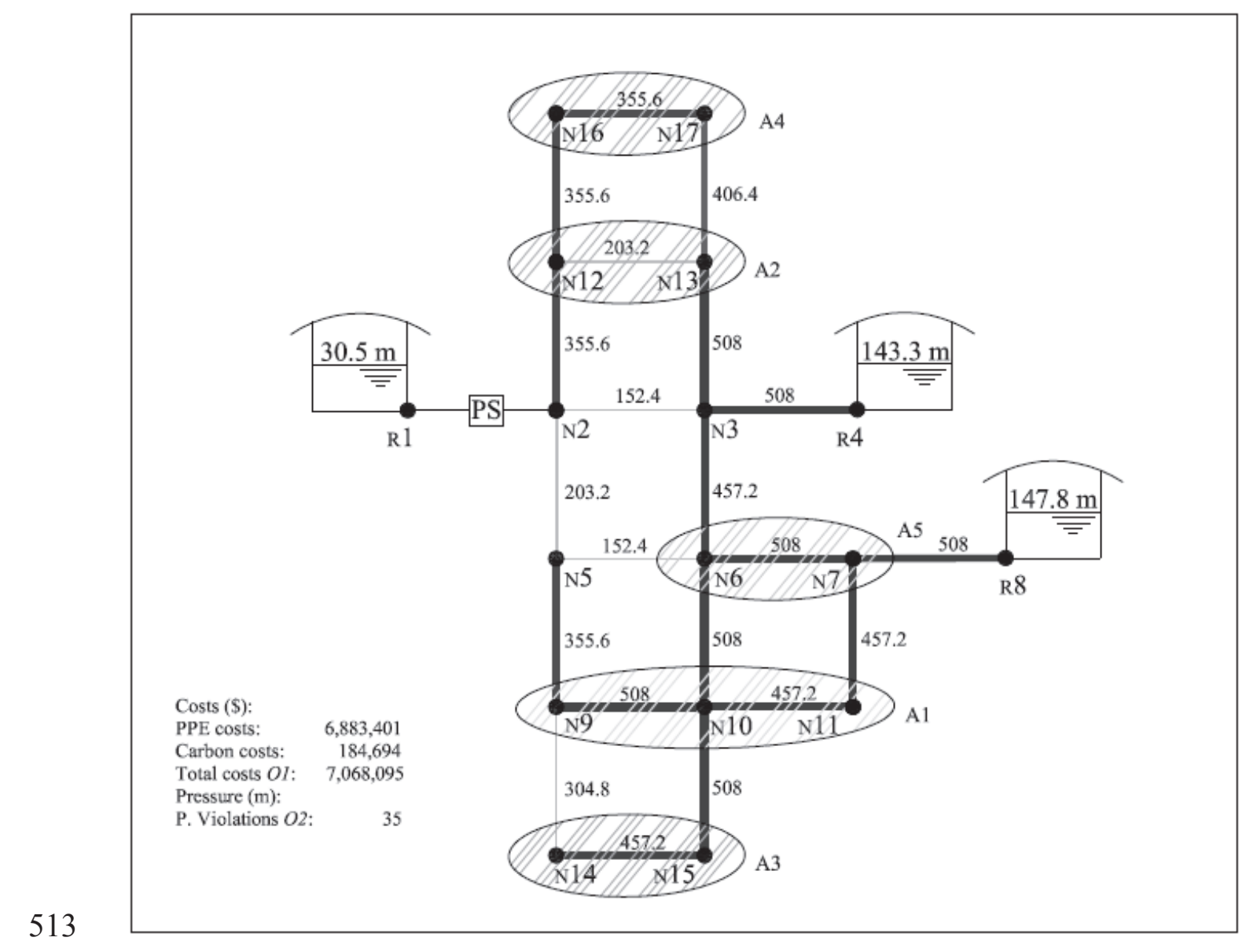

514 Figure 7: Design for solution 10 and considering scenario 1 for the last time interval In terms of violations, solution 1 , for scenario 1 , has $18 \mathrm{~m}$ and solution 10 , for

516 scenario 1, has $35 \mathrm{~m}$ total minimum pressure violations. Differences between solutions

517 indicate that a cost increment of $6 \%$ is needed for scenario 1 to lower the total minimum

518 pressure violations by $17 \mathrm{~m}$. Also, the carbon emission costs increase $6 \%$ if a network

519 with low pressure violations is required.

The optimization model aims to simultaneously minimize the installation,

521 operation and carbon emission costs of the first objective function OF1. But it also aims

522 to minimize the pressure violations given by objective function $O F 2$. The designs

523 represented by Figs 6 and 7 can be used as solutions for the case study described in this

524 work if scenario 1 occurs. However, other solutions given by the multi-objective model

525 can be chosen, according to the preferences of decision makers. All the possible 
decision paths of solution 1 of the Pareto front in Fig. 5 determined by the multi-

527 objective tool, are shown in greater detail in Fig. 8.

Decisions have to be made for each time interval of the decision tree. Fig. 8 presents, for each node, a table with the results of design solution 1 of the Pareto front, beginning with the diameters of pipes (in millimeters) required in the network. Then the costs are shown, divided into PPE costs, carbon costs, total cost and minimum pressure violations. Finally, the last branches of the decision tree represent the total cost of PPE, carbon emissions, total cost and total pressure violations for each scenario. These figures represent, for each scenario, the total cost and pressure violations that may be expected if that scenario occurs.

Only the first stage design decision has to be implemented now, and therefore the future decisions will be made as new information comes. At the end of each phase

538 the methodology should be applied again and different scenarios from those considered

539 initially could be considered (Creaco et al. 2014). The ROs approach is formulated as a

540 multi-stage model whose objective is to design the network for the first time interval

541 and help decision makers to find the best system development strategy while

542 minimizing the costs.

The design for the network depends not only on the hydraulic conditions of the

544 present decision but on the decision paths that can be followed, too. The decisions taken

545 in prior stages have to accommodate the future possible conditions of the network. The

546 ROs approach considers different scenarios with different probabilities. By adding

547 together the initial cost and all the future weighted costs we can arrive at the present

548 value of the ROs solution in the Pareto front, which is $\$ 5.945 \times 10^{6}$. The sum of all

549 pressure violations at the nodes of the network for this solution is $23 \mathrm{~m}$. 


\begin{tabular}{|c|c|c|c|c|c|c|c|}
\hline \multirow{2}{*}{\multicolumn{2}{|c|}{$T=1(0$ to 20 years $)$}} & \multirow{2}{*}{\multicolumn{2}{|c|}{$T=2(20$ to 40 years $)$}} & \multirow{2}{*}{\multicolumn{2}{|c|}{$T=4(40$ to 60 years $)$}} & \multirow{2}{*}{\multicolumn{2}{|c|}{$\begin{array}{l}\text { Decision paths } \\
\text { (0 to } 60 \text { years) } \\
\end{array}$}} \\
\hline & & & & & & & \\
\hline & & & & Expansi & $\mathrm{A} 3 / \mathrm{A} 4$ & Scer & \\
\hline & & & & $\mathrm{New}$ & ipes & Objective fi & a values \\
\hline & & & & links & Diam. (mm) & & \\
\hline & & & & 17 & 152.4 & $\begin{array}{l}\text { PPE costs } \\
\text { Carbon costs }\end{array}$ & 195,925 \\
\hline & & & & 18 & 508 & Total costs & $7,455,992$ \\
\hline & & & & 19 & $\begin{array}{c}508 \\
3048\end{array}$ & P. violations & \\
\hline & & & & 21 & 508 & & \\
\hline & & & & 22 & 304.8 & & \\
\hline & & & & Objective fi & ction values & & \\
\hline & & & & PPE costs & 807,756 & & \\
\hline & & Expansi & $\mathrm{A} 1 / \mathrm{A} 2$ & Carbon costs & 22,422 & & \\
\hline & & & & $\begin{array}{l}\text { Total costs } \\
\text { P. violations }\end{array}$ & $\begin{array}{r}830,179 \\
18\end{array}$ & & \\
\hline & & & Diam. (mm) & Exnan & & & \\
\hline & & 9 & 254 & $\begin{array}{r}\text { Expan } \\
\mathrm{P}\end{array}$ & on $\mathrm{A}^{3}$ & Scer & walues \\
\hline & & 10 & 457.2 & Links & & Objective fu & a values \\
\hline & & 11 & 508 & 17 & 203.2 & PPE costs & $7,005,656$ \\
\hline & & 12 & 406.4 & 18 & 508 & Carbon costs & 189,287 \\
\hline & & 13 & 508 & 19 & 406.4 & Total costs & $7,194,943$ \\
\hline & & 14 & $\begin{array}{c}406.4 \\
508\end{array}$ & Objective $\mathrm{ft}$ & ction values & & \\
\hline & & $\begin{array}{l}15 \\
16\end{array}$ & $\begin{array}{c}508 \\
2032\end{array}$ & PPE costs & 553,345 & & \\
\hline & & & & Carbon costs & 15,785 & & \\
\hline & & Objective fi & tion values & Total costs & 569,129 & & \\
\hline Initial & blution & PPE costs & $2,147,184$ & P. violations & & & \\
\hline & & Carbon costs & 58,034 & Expan & on $\mathrm{A} 4$ & Scer & \\
\hline links & Diam. $(\mathrm{mm})$ & Total costs & $2,205,218$ & & & Objective f & values \\
\hline 2 & 152.4 & & & Links & Diam. (mm) & PPE costs & $6.973,213$ \\
\hline 3 & 508 & & & 20 & 304.8 & $\begin{array}{l}\text { PPE costs } \\
\text { Carbon costs }\end{array}$ & $\begin{array}{r}6,973,213 \\
189,171\end{array}$ \\
\hline 4 & 254 & & & 21 & 508 & Total costs & $7,162,385$ \\
\hline $\begin{array}{l}5 \\
6\end{array}$ & $\begin{array}{l}457.2 \\
304.8\end{array}$ & & & 22 & 304.8 & P. violations & 0 \\
\hline $\begin{array}{l}6 \\
7\end{array}$ & $\begin{array}{c}304.8 \\
508\end{array}$ & & & $\begin{array}{l}\text { Objective fi } \\
\text { PPE costs }\end{array}$ & $\frac{\text { ction values }}{520,902}$ & & \\
\hline 8 & 508 & & & Carbon costs & $\begin{array}{r}52,902 \\
15,669\end{array}$ & & \\
\hline Objective fi & ction values & & & Total costs & 536,571 & & \\
\hline PPE costs & $4,305,128$ & & & P. violations & & & \\
\hline Carbon costs & 115,468 & & & Expan & on $\mathrm{A} 3$ & Scer & \\
\hline Total costs & $4,420,596$ & Expan & on $\mathrm{Al}$ & & & Objective f & a values \\
\hline P. Violation & & & & Links & Diam. (mm) & PPE costs & $5,879,244$ \\
\hline & & links & Diam. (mm) & $\begin{array}{l}17 \\
18\end{array}$ & $\begin{array}{c}203.2 \\
508\end{array}$ & Carbon costs & 164,507 \\
\hline & & 9 & 152.4 & 19 & 508 & $\begin{array}{l}\text { Total costs } \\
\text { P }\end{array}$ & $6,043,751$ \\
\hline & & 10 & $\begin{array}{c}508 \\
3048\end{array}$ & Objective fi & ction values & P. violations & \\
\hline & & 11 & 304.8 & PPE costs & 534,903 & & \\
\hline & & 12 & 203.2 & Carbon costs & 14,678 & Scer & \\
\hline & & & & Total costs & 549,581 & Objective f & a values \\
\hline & & Objective $\mathrm{f}$ & ction values & P. violations & & PPF costs & $5.584,485$ \\
\hline & & PPE costs & $1,039,214$ & Do no & xpand & $\begin{array}{l}\text { PPE costs } \\
\text { Carbon costs }\end{array}$ & $\begin{array}{r}5,584,485 \\
157,482\end{array}$ \\
\hline & & $\begin{array}{l}\text { Carbon costs } \\
\text { Total costs }\end{array}$ & $\begin{array}{r}34,361 \\
1.073,574\end{array}$ & PPE costs & 240,144 & Total costs & $5,741,967$ \\
\hline & & $\begin{array}{l}\text { 1otal costs } \\
\text { P. violations }\end{array}$ & $\begin{array}{r}1,0 / 3,5 / 4 \\
0\end{array}$ & Carbon costs & 7,653 & P. violations & \\
\hline & & & & Total costs & 247,797 & & \\
\hline & & & & P. violations & & Scer & \\
\hline & & & & Expan & on $\mathrm{A} 4$ & Objective fi & a values \\
\hline & & Expar & on A2 & & & & \\
\hline & & & & Links & Diam. $(\mathrm{mm})$ & Carbon costs & $\begin{array}{r}5,168,155 \\
161,135\end{array}$ \\
\hline & & & Diam. (mm) & 20 & $\begin{array}{l}254 \\
508\end{array}$ & Total costs & $5,929,290$ \\
\hline & & 14 & 355.6 & 22 & 304.8 & P. violations & \\
\hline & & 15 & 406.4 & Objective fi & ction values & & \\
\hline & & & 203.2 & PPE costs & 501,823 & Scer & \\
\hline & & Objective $\mathrm{ft}$ & tion values & Carbon costs & 15,276 & Objective $\mathrm{ft}$ & a values \\
\hline & & PPE costs & 961,204 & $\begin{array}{l}\text { Total costs } \\
\text { P. violations }\end{array}$ & $\begin{array}{r}517,099 \\
0\end{array}$ & PPE costs & $5,539,938$ \\
\hline & & $\begin{array}{l}\text { Carbon costs } \\
\text { Total costs }\end{array}$ & $\begin{array}{r}30,391 \\
991,595\end{array}$ & 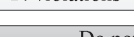 & & Carbon costs & 154,684 \\
\hline & & P. violations & $\begin{array}{r}991,595 \\
0\end{array}$ & $\begin{array}{l}\text { Do no } \\
\text { PPE costs }\end{array}$ & xpand & Total costs & $5,694,622$ \\
\hline & & & & Carbon costs & $\begin{array}{r}273,606 \\
8,825\end{array}$ & P. violations & \\
\hline & & & & Total costs & 284,431 & & \\
\hline & & Do no & spand & P. violations & 0 & Scer & \\
\hline & & PPE costs & 496,801 & Deponu & $\operatorname{tion} \mathrm{A} 5$ & Objective fi & a values \\
\hline & & Carbon costs & 15,827 & $\begin{array}{l}\text { Depopu } \\
\text { PPE costs }\end{array}$ & 226.734 & PPE costs & $5,028,663$ \\
\hline & & Total costs & 512,628 & Carbon costs & $\begin{array}{r}22,7,34 \\
7,223\end{array}$ & Carbon costs & 138,519 \\
\hline & & P. violations & & Total costs & 233,957 & Total costs & $5,167,181$ \\
\hline & & & & P. violations & 0 & P. violations & \\
\hline
\end{tabular}

$553 \quad$ Figure 8: Designs for solution 1 according to the planning horizon decision tree 
556 future new areas that may be built. Pipes 2 to 8 (see Fig. 1) are designed in the first

557 stage, but need to have enough capacity for different decision paths. However, there is a

558 tradeoff to determine the minimum cost solution involving carbon emissions and the

559 minimum pressure violations that are allowed in the planning horizon.

\section{6 conclusions}

561 An ROs approach has been described that takes future uncertainties into account and

562 deals with conflicting objectives over the whole planning horizon. A case study has

563 been detailed with some possible expansion areas defined for different future scenarios.

564 This was followed by a multi-objective decision model based on an ROs approach. The model aims to minimize two objectives and cope with all the different planning horizon

566 scenarios that are considered. The objective functions and their constraints determine

567 the solutions to be implemented in the first period, $\mathrm{T}=1$, while taking into account all

568 the possible future conditions that the network may have to cope with. ROs enable initial investments to be reduced by postponing some decisions for the future.

The model aims to minimize two objectives. The first is given by the total cost computed as the sum of the installation cost of pipes and pumps plus the energy costs and the carbon cost over the lifecycle of the network. These costs are actualized to year zero and weighted by the probabilities of the future scenarios. The second objective is to minimize the minimum desirable pressure violations computed by summing the extent of the violation for all the nodes of the network and for all the scenarios. This objective can be seen as a level of service measure for the water supply system. The model is

577 solved by a multi-objective simulated annealing heuristic and the results are represented 
as points on the Pareto front. Carbon emissions are considered in the model. These environmental impacts are reduced by decreasing the size of the diameters and by cutting energy consumption. But, in this case study, there is a relationship between the pipe design and the energy consumed by pumps. Energy consumption can be reduced by using large pipe diameters that decrease the head losses, thereby reducing the amount of energy required to pump water. The optimization model has to handle this tradeoff.

A group of solutions is obtained by the multi-objective model. These results enable decision makers to choose which solution to implement according to some preferences. One of these solutions is shown in more detail by means of a decision tree, including the values for the different decision variables, the total investment, the operating and carbon emission costs that will be incurred, and the minimum pressure violations.

From the results, it was concluded that the carbon emission costs do not have a significant influence on the objective function value. As future trends, carbon emission costs should be included explicitly in the multi-objective optimization model to express the compromise between the minimization of these eco-friendly aspects and the other objectives. Furthermore, energy and pipe costs are conflicting with each other and the cost of energy could be viewed as another distinct objective to optimize.

Overall, this study suggests that the multi-objective optimization tool based on ROs and considering environmental impacts can be used for solving water network design and operation problems with a long-term and uncertain planning horizon. The results also suggest that a multi-objective simulated annealing method can be successfully applied, leading to sparse Pareto front solutions. 


\section{Acknowledgments}

This work has been financed by FEDER funds through the Programa

Operacional Factores de Competitividade - COMPETE, and by national funds from

FCT -Fundação para a Ciência e Tecnologia under grant PTDC/ECM/64821/2006. The participation of the first author in the study is supported by FCT - Fundação para a Ciência e Tecnologia through Grant SFRH/BD/47602/2008.

\section{References}

Ahmadi, M., Arabi, M., Ascough, J. C., Fontane, D. G., and Engel, B. A. (2014). Toward improved calibration of watershed models: Multisite multiobjective measures of information. Environmental Modelling \& Software, 59, 135-145.

Bandyopadhyay, S., Saha, S., Maulik, U., and Deb, K. (2008). A Simulated AnnealingBased Multiobjective Optimization Algorithm: AMOSA. Evolutionary Computation, IEEE Transactions on.

Basupi, I., and Kapelan, Z. (2013). Flexible Water Distribution System Design under Future Demand Uncertainty. Journal of Water Resources Planning and Management.

Creaco, E., and Franchini, M. (2012). Fast network multi-objective design algorithm combined with an a posteriori procedure for reliability evaluation under various operational scenarios. Urban Water Journal, 9(6), 385-399.

Creaco, E., Franchini, M., and Walski, T. (2014). Accounting for Phasing of Construction within the Design of Water Distribution Networks. Journal of Water Resources Planning and Management, 140(5), 598-606.

Cunha, M., and Sousa, J. (2001). Hydraulic Infrastructures Design Using Simulated Annealing. Journal of Infrastructure Systems, 7(1), pp. 32-39.

Dandy, G., Roberts, A., Hewitson, C., and Chrystie, P. (2006). Sustainability Objectives For The Optimization Of Water Distribution Networks. In W. D. S. A. S. 2006 (Ed.), Water Distribution Systems Analysis Symposium 2006 (pp. 1-11). American Society of Civil Engineers.

De Neufville, R., Scholtes, S., and Wang, T. (2006). Real Options by Spreadsheet: Parking Garage Case Example. Journal of Infrastructure Systems, 12(2), 107-111. 
Dennison, F. J., Azapagic, A., Clift, R., and Colbourne, J. S. (1999). Life cycle assessment: Comparing strategic options for the mains infrastructure - Part I. Water Science and Technology, 39(10-11), 315-319.

Di Pierro, F., Khu, S.-T., Savić, D., and Berardi, L. (2009). Efficient multi-objective optimal design of water distribution networks on a budget of simulations using hybrid algorithms. Environ. Model. Softw., 24(2), 202-213.

ERSE. (2012). Comércio Europeu de Licenças de Emissão de Gases com Efeito de estufa (p. 30).

Farmani, R., Savic, D., and Walters, G. (2004). The Simultaneous Multi-Objective Optimization of Anytown Pipe Rehabilitation, Tank Sizing, Tank Siting, and Pump Operation Schedules. In Critical Transitions in Water and Environmental Resources Management (pp. 1-10). American Society of Civil Engineers.

Fonseca, C. M., and Fleming, P. J. (1993). Genetic Algorithms for Multiobjective Optimization: FormulationDiscussion and Generalization. In Proceedings of the 5th International Conference on Genetic Algorithms (pp. 416-423). San Francisco, CA, USA: Morgan Kaufmann Publishers Inc.

Gersonius, B., Ashley, R., Pathirana, A., and Zevenbergen, C. (2010). Managing the flooding system's resiliency to climate change. Proceedings of the Institution of Civil EngineersEngineering Sustainability, 163(1), 15-22.

Giuliani, M., Galelli, S., and Soncini-Sessa, R. (2014). A dimensionality reduction approach for many-objective Markov Decision Processes: Application to a water reservoir operation problem. Environmental Modelling \& Software, 57, 101-114.

Haimes, Y. Y. (1998). Sustainable Operation of Threatened Infrastructures. Journal of Infrastructure Systems, 4(1), 1-4.

Hakanen, J., Sahlstedt, K., and Miettinen, K. (2013). Wastewater treatment plant design and operation under multiple conflicting objective functions. Environmental Modelling \& Software, 46, 240-249.

Hartigan, J. A., and Wong, M. A. (1979). Algorithm AS 136: A k-means clustering algorithm. Applied Statistics, 28(1), 100-108.

Herstein, L., Filion, Y., and Hall, K. (2011). Evaluating the Environmental Impacts of Water Distribution Systems by Using EIO-LCA-Based Multiobjective Optimization. Journal of Water Resources Planning and Management, 137(2), $162-172$.

Huang, D., Vairavamoorthy, K., and Tsegaye, S. (2010). Flexible Design of Urban Water Distribution Networks. In World Environmental and Water Resources Congress (pp. 4225-4236).

Kirkpatrick, S., Jr., C. D. G., and Vecchi, M. P. (1983). Optimization by simmulated annealing. Science, 220(4598), 671-680. 
Marques, J. C. R.; Cunha, M. C.; Savic, D. (2014a) "Using Real Options for an Ecofriendly Design of Water Distribution Systems". Journal of Hydroinformatics In Press, IWA Publishing 2014 | doi:10.2166/hydro.2014.122

Marques, J. C. R.; Cunha, M. C.; Savic, D. (2014b) “Using Real Options in the Optimal Design of Water Distribution Networks". Journal of Water Resources Planning and Management, n. 1274. accepted for publication.

Myers, S. C. (1977). Determinants of corporate borrowing. Journal of Financial Economics, 5(2), 147-175.

Nembhard, H. B., and Aktan, M. (2010). Real options in engineering design, operations, and management. Production Planning \& Control, 21(7), 718-719.

Pareto, V. (1896). Cours d'Economie Politique. Genl`eve: Droz.

Prasad, T. D., Hong, S.-H., and Park, N. (2003). Reliability based design of water distribution networks using multi-objective genetic algorithms. KSCE Journal of Civil Engineering, 7(3), 351-361.

Rossman, L. A. (2000). Epanet 2 users manual. (U. S. E. P. Agency, Ed.)Cincinnati US Environmental Protection Agency National Risk Management Research Laboratory, 38(September), 200.

Sacks, J., Welch, W. J., Mitchell, T. J., and Wynn, H. P. (1989). Design and Analysis of Computer Experiments. Statistical Science, 4(4), 409-423.

Savic, D. (2002). Single-objective vs. Multiobjective Optimisation for Integrated Decision Support,. In In: Integrated Assessment and Decision (pp. 7-12).

Suttinon, P., and Nasu, S. (2010). Real Options for Increasing Value in Industrial Water Infrastructure. Water Resources Management, 24(12), 2881-2892.

Todini, E. (2000). Looped water distribution networks design using a resilience index based heuristic approach. Urban Water, 2(2), 115-122.

Wagner, J. M., Shamir, U., and Marks, D. H. (1988). Water Distribution Reliability: Simulation Methods. Journal of Water Resources Planning and Management, 114(3), 276-294.

Walski, T. M., Gessler, J., and Sjostrom, J. W. (1990). Water distribution systems: Simulation and sizing. (M. Wentzel, Ed.)Environmental Progress (p. 321). Chelsea: Lewis Publishers.

Woodward, M., Gouldby, B., Kapelan, Z., Khu, S.-T., and Townend, I. (2011). Real Options in flood risk management decision making. Journal of Flood Risk Management, 4(4), 339-349. 
703

704

705

706

707

708

709

710

711

712

713

Wu, W., Simpson, A. R., and Maier, H. R. (2010). Accounting for Greenhouse Gas Emissions in Multiobjective Genetic Algorithm Optimization of Water Distribution Systems. Journal of Water Resources Planning and Management, 136(5), 146-155.

Zhang, S. X., and Babovic, V. (2012). A real options approach to the design and architecture of water supply systems using innovative water technologies under uncertainty. Journal of Hydroinformatics, 14(1), 13-29.

Zheng, F., and Zecchin, A. (2014). An efficient decomposition and dual-stage multiobjective optimization method for water distribution systems with multiple supply sources. Environmental Modelling \& Software, 55, 143-155. 